\title{
Evaluation of Continuous Gas Lift Systems in an Oil Well
}

\author{
Hisham Khaled Ben Mahmud and Vincent Goenawan
}

\author{
Department of Petroleum Engineering, Curtin University, Sarawak, Malaysia
}

\begin{abstract}
Continuous gas lift is a technology used by injecting a highly compressed gas to decrease the density of fluid column hence provide an additional lifting energy to increase the production performance of an oil well. The continuous gas lift system is evaluated based on the capabilities to overcome the well and reservoir condition. Therefore, the objective of this paper is to distinguish the capabilities of continuous gas lift system in different type of well characteristics. An oil well C-06 is used as the case study well where the simulation is evaluated through PROSPER software. A model is developed to perform history matching with field production data to verify the results and to perform a sensitivity analysis on the liquid production. The result shows that the continuous gas lift application increases the liquid production rate up to 1,864.6 STB/d from a non-producing oil well.
\end{abstract}

Keywords: continuous gas lift, artificial lift, liquid rate, simulation, oil well, PROSPER.

\section{INTRODUCTION}

The natural production of an oil well is obtained when the reservoir pressure is able to overcome the bottom-hole flowing pressure, which is the sum of wellhead, hydrostatic and tubing frictional pressure. The reservoir pressure is highly depending on the type of the primary reservoir drive mechanisms such as gas cap, depletion and water drive mechanism (Ahmed et. al. 2012). When the bottom-hole pressure is greater than the reservoir pressure, the natural production is stopped hence artificial lift is applied to provide an additional lifting energy.

Artificial lift is a technology used in subsequent stages to provide an additional lifting energy to extract out the fluid to the surface from its low reservoir natural lifting energy supply. The selection of artificial lift methods is depending on the well characteristic whereas in this paper, the focused method to be analyzed is the continuous gas lift. Continuous gas lift uses an external source of high compressed gas injected into the well through the tubing annulus by a surface compressor (Hirsch et. al. 2006). The application of continuous gas lift brings the fluid to the surface by reducing the density of the fluid in the wellbore hence minimizes the flowing pressure and increases the production rate.

\subsection{Statement of Problem, Objective and Limitation of Study}

The initial reservoir pressure reduces over production time hence continuous depletion of the reservoir pressure causes an insufficient pressure to overcome the bottom-hole flowing pressure. This condition results in a non-economical production performance or stops the production in the extreme case scenario.

The objective of this study is to evaluate the application of continuous gas lift in an oil well. Initial well screening and sensitivity analysis were done by altering different parameters that affect the bottom-hole pressure which include: water cut and reservoir pressure. Also, optimization of continuous gas lift application is done by manipulating the gas lift parameters such as injection depth, injection rate, gas specific gravity and wellhead pressure. However, the study will not explain the effect of continuous gas lift application in a different well types and well completion method.

\section{MeThodology}

\subsection{Initial Well Screening}

Artificial lift methods have different capabilities in terms of handling different types of wells. Therefore, initial well screening is necessary to ensure the ability of continuous gas lift to be applied in the case study well, C-06 by considering the well depth and production rates. The allowable depth 
and rates range of each method are shown in Figure 1. The well C-06 has a depth of 9,680 ft with the absolute open flow of 3,240 STB/day. Accordingly, both depth and rate can be operated under the application of continuous gas lift.

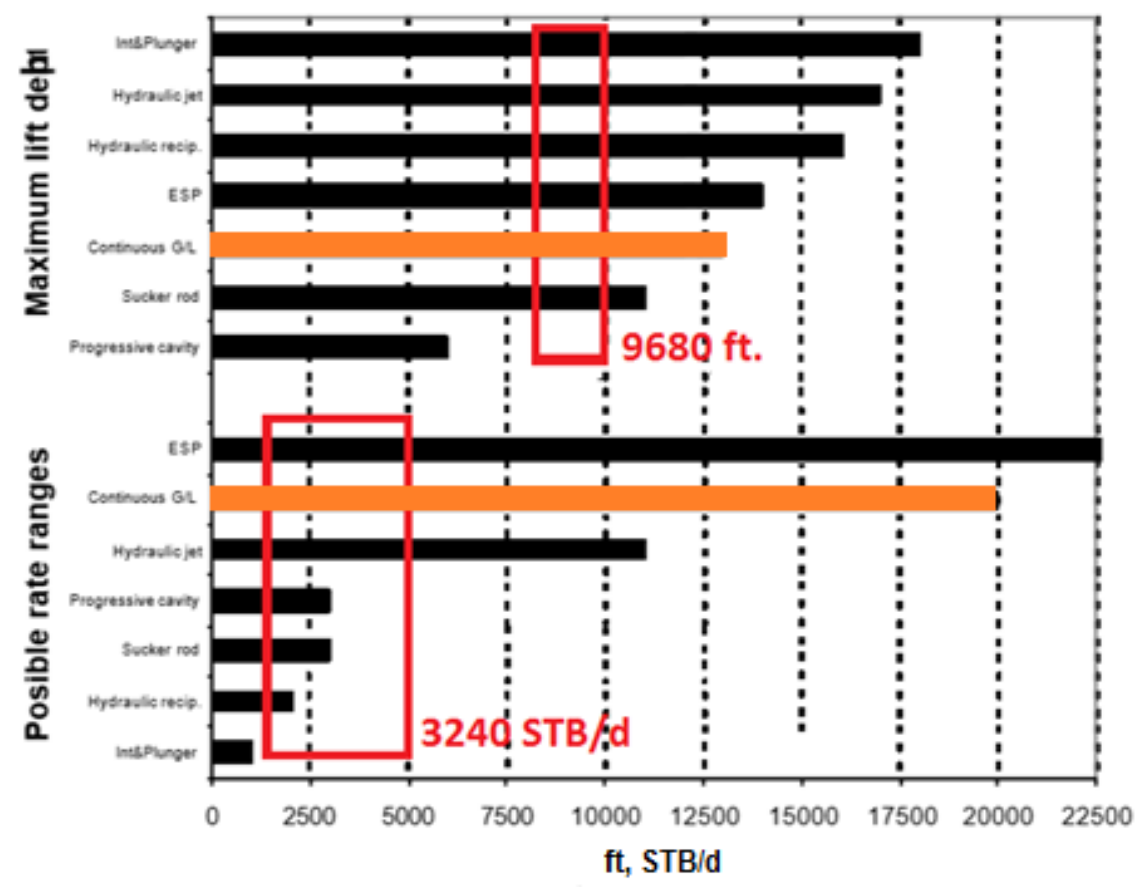

Figure1. Artificial lift methods initial well screening (Ramirez, 2000)

\subsection{Building A Base Model}

In this paper, the virtual base model was constructed using PROSPER and tuned based on the available information of well C-06. The properties of the initial well C-06 are listed in Table 1.

Table1. Well C-06 initial well properties

\begin{tabular}{|c|c|}
\hline Properties & Value \\
\hline Fluid & Oil and water \\
\hline Flow type & Tubing flow \\
\hline Solution GOR (scf/STB) & 200 \\
\hline Oil gravity (API) & 30 \\
\hline Gas gravity (sp.gravity) & 0.75 \\
\hline Water salinity (ppm) & 35000 \\
\hline Temperature (C) & 60 \\
\hline Bubble point (psig) & 650 \\
\hline Reservoir pressure (psig) & 2500 \\
\hline Reservoir temperature (C) & 64 \\
\hline Water cut (\%) & 15 \\
\hline Productivity index (STB/day/psi) & 1.8 \\
\hline Well depth (ft) & 9690 \\
\hline True vertical depth (ft) & 9690 \\
\hline 9" Casing depth (ft) & 3141 \\
\hline 7" Casing depth (ft) & 7260 \\
\hline 3" Casing depth (ft) & 9688 \\
\hline 3" Tubing depth (ft) & 8723 \\
\hline Oil heat capacities (BTU/lb/F) & 8 \\
\hline Gas heat capacities (BTU/lb/F) & 0.53 \\
\hline Water heat capacities (BTU/lb/F) & 0.3 \\
\hline
\end{tabular}

\subsection{Building a Continuous Gas Lift Model}

The continuous gas lift is designed to be applied into the simulated well C-06 whereas the basic properties of the continuous gas lift are shown in Table 2. 
Table2.Continuous gas lift modelling

\begin{tabular}{|c|c|}
\hline Properties & Value \\
\hline Maximum liquid rate (STB/d) & 4000 \\
\hline Flowing top node pressure (psig) & 300 \\
\hline Unloading top node pressure (psig) & 300 \\
\hline Operating injection pressure (psig) & 1000 \\
\hline Kick off injection pressure (psig) & 1000 \\
\hline dP across valve (psi) & 50 \\
\hline Water cut (\%) & 15 \\
\hline
\end{tabular}

\section{Well Performance}

\subsection{Initial Well Performance}

The initial well performance is first analyzed where the main source of the lifting energy is from the reservoir pressure. The initial reservoir is highly depending on the type of drive mechanism of the well wherein well C-06, the drive mechanism is the combination of aquifer and gas cap.

As described in Figure 2, it is observed that the reservoir pressure is initially at 2,300 psia with the Absolute Open Flow (AOF) of 3,240 STB/day. Respectively, it is plotted in the green curve named as IPR curve. Whereas the red curve, Vertical Lift Performance which comprises of the wellhead and hydrostatic pressure lies far above the IPR curve. Consequently, there is no intersection between the two curves hence no initial well production is performed.

The absence of the initial well production is due to insufficient reservoir pressure to overcome the bottom-hole pressure. According to the well designed, the total well depth is 9,680 ft. with the oil density of 30 API, hence giving the total hydrostatic pressure of 3,398 psia. Adding the wellhead pressure of 600 psia resulting in a total bottom-hole pressure of 4,000 psia to be covered by the reservoir pressure to produce the fluid to the surface (Denney, 1999). In fact, the reservoir pressure is only 2,350 therefore the initial well condition is lacking 1,700 psia to produce the fluid from the bottom hole to the surface.

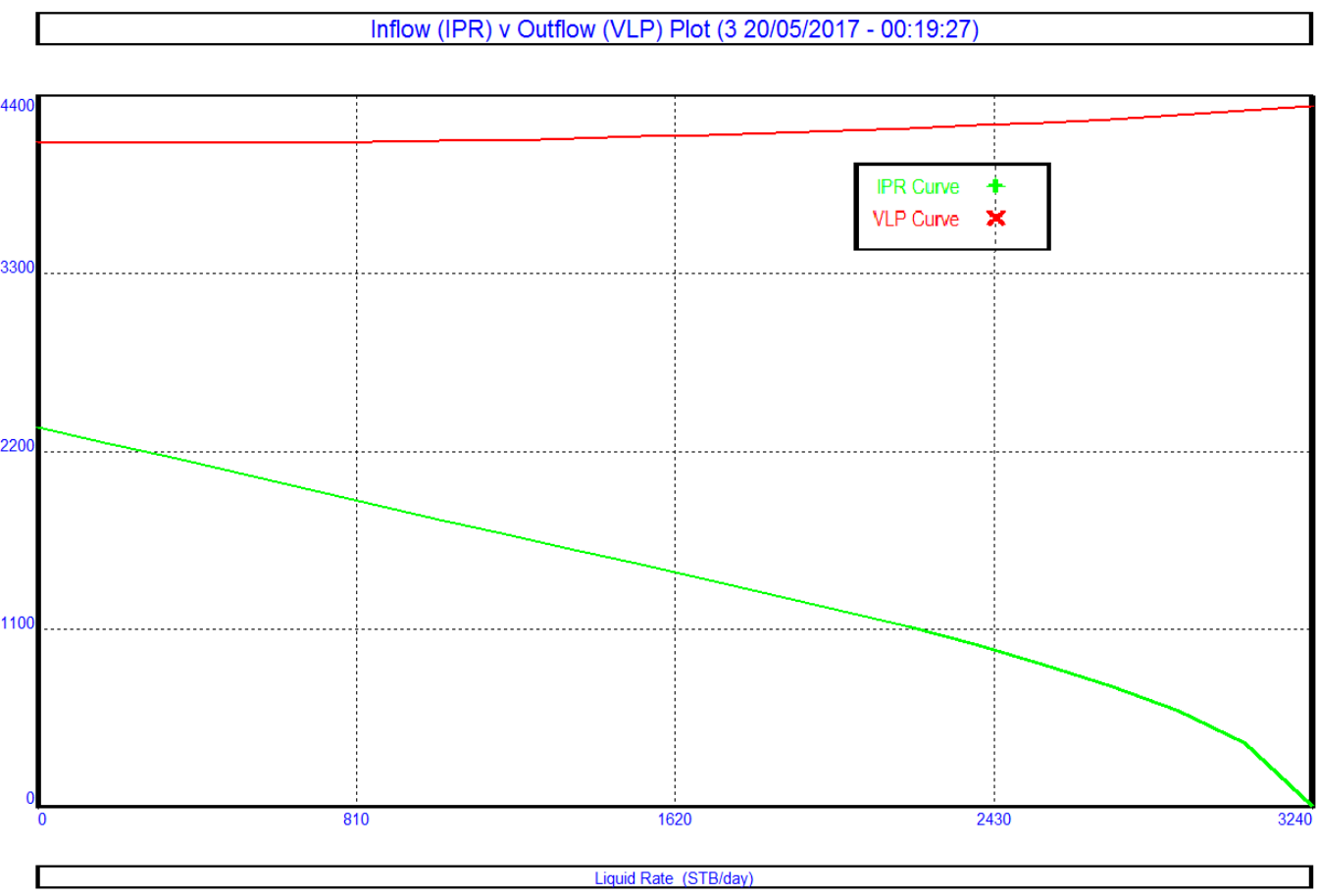

Figure2. IPR VS VLP plot of initial well performance

\subsection{Continuous Gas Lift Application}

The continuous gas lift is applied to the initial well C-06 with a total of four valves. The compressed gas from the surface flow through the casing annulus down the drill-string and enter the production tubing through three unloading valves located at 7,000, 7,500 and 8,000 feet and one operating valve at 8,699 feet. The illustration of the continuous gas lift down-hole design is shown in Figure 3 


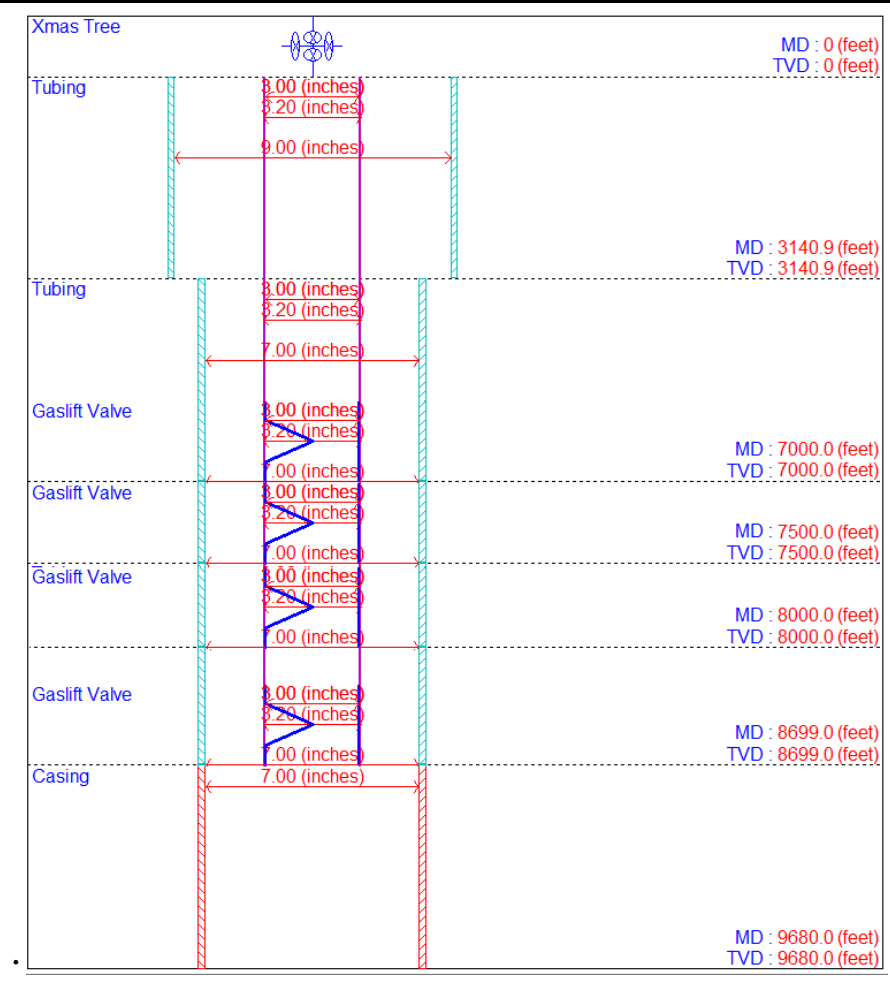

Figure3. Down-hole design of continuous gas lift application

From the corresponding design, the result of the continuous gas lift application is plotted in Figure 4. It is observed that the VLP curve has been decreased from initially 4,100 psia to only 995 psia. Respectively, the new VLP curves with the application of continuous gas lift application intersect the IPR curve at a total liquid production of 1,410.2 STB/D.

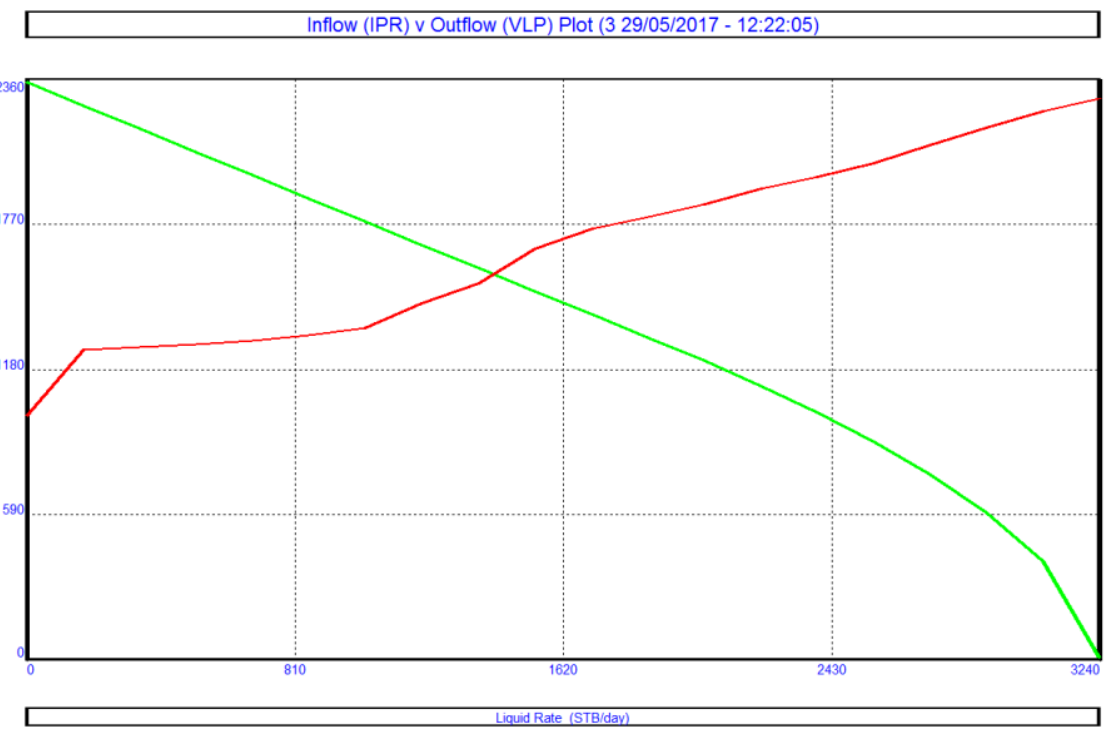

Figure4. IPR VS VLP plot of continuous gas lift application

\section{SEnSitivity AnAlysis}

Every reservoir has different characteristics such as pressure, water cut, temperature and gas oil ratio depending on the location, depth, and drive mechanism of the reservoir. Accordingly, the production performance of the well is strongly depending on the mentioned parameters whereas the application of the artificial lift methods is relevantly affected. Hence, the evaluation of the reservoir characteristic is important prior the selection of the optimum artificial lift method.

\subsection{Water Cut}

Water cut describes the volume of water contained in the fluid column and represented in the percentage form. The source of the water is mostly through the types of the drive mechanism where 
strongest water supply is obtained from the aquifer drive mechanism. Theoretically, the high volume of water in the fluid column to be produced reduces the rate of total liquid produced as it has heavy density compared to other three major fluid produced: oil, water and gas (Boucher et. al. 2011). Respectively, higher density to be lifted up occurs in a high water cut. The analysis of the change in water cut in the reservoir is conducted in the continuous gas lift and ESPs to distinguish the ability of each to deal with the change of water cut. Manipulation of water cut varies from $0 \%$ to $90 \%$ where the results are plotted in Figure 5.

It is observed that from the water cut manipulation, the total liquid production rate is decreased gradually with the increase of water cut as tabulated in Table 3 . However, as the studied field is not a strong aquifer, where it initially has $20 \%$ of water cut, the prediction of water cut increment over time is approximately up to $50 \%$. Hence, the evaluation of water cut to be considered is from $20 \%$ to $50 \%$.

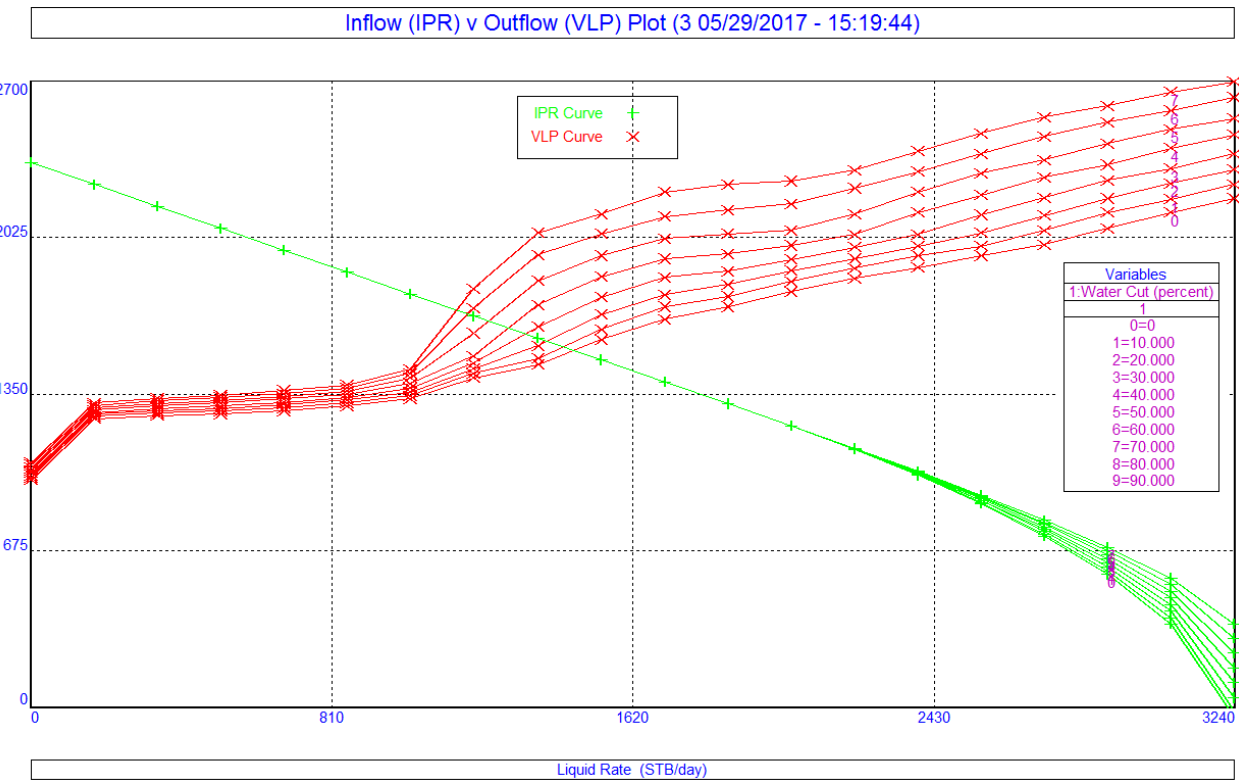

Figure5. Water cut sensitivity analysis on continuous gas lift application

Table3. Results of water cut sensitivity analysis

\begin{tabular}{|c|c|}
\hline Water Cut $(\%)$ & Liquid Production Rate (STB/D) \\
\hline 0 & 1461.0 \\
\hline 10 & 1432.8 \\
\hline 20 & 1389.4 \\
\hline 30 & 1332.7 \\
\hline 40 & 1287.8 \\
\hline 50 & 1234.7 \\
\hline
\end{tabular}

\subsection{Reservoir Pressure}

Reservoir pressure is the pressure exerted from the reservoir to lift the hydrocarbon all the way up to the surface. The reservoir pressure reduces with time where the amount of reduction is depending on the reservoir mechanism. Consequently, the lesser the reservoir pressure performs a lower production rate. Thus, reservoir pressure is used for well potential production rate prediction and particularly for assessing the effect of artificial lift application.

The drive mechanism in well C-06 is aquifer-based wherein water drive mechanism, there is a slight decrease of reservoir pressure over time (Kaczorowski, 1993). Hence, the simulation is done by reducing the initial reservoir pressure gradually from 2,350 to 2,000 psia. The respective attempts are plotted in Figure 6 and the results are listed in Table 4.

It is found that the total liquid production reduces with the decrease of reservoir pressure as theoretically studied. 


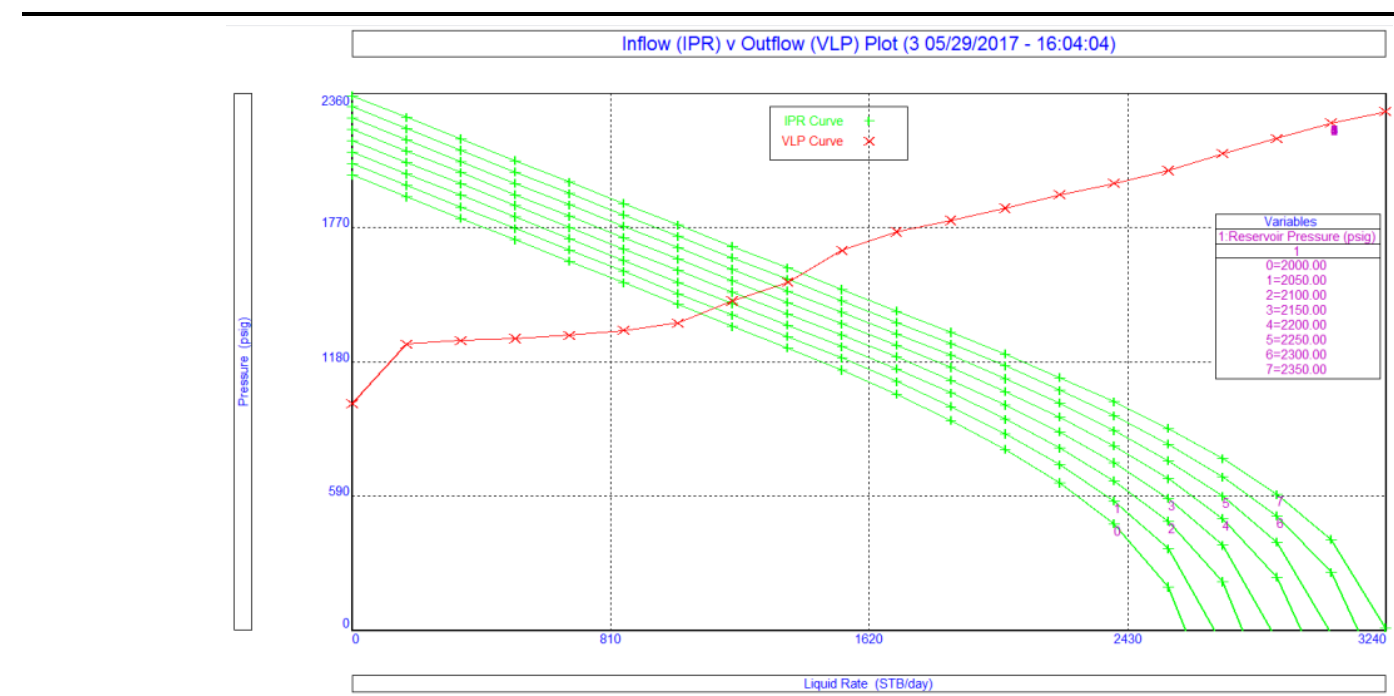

Figure6. Reservoir pressure sensitivity analysis on gas lift application

Table4. Results of reservoir pressure sensitivity analysis

\begin{tabular}{|c|c|}
\hline Reservoir Pressure (psig) & Liquid Production Rate (STB/D) \\
\hline 2350 & $1,409.6$ \\
\hline 2300 & $1,373.0$ \\
\hline 2250 & $1,327.4$ \\
\hline 2200 & $1,279.3$ \\
\hline 2150 & $1,231.2$ \\
\hline 2100 & $1,184.0$ \\
\hline 2050 & $1,139.7$ \\
\hline 2000 & $1,095.4$ \\
\hline
\end{tabular}

\section{Continuous Gas Lift Optimization}

Numerous of gas lift parameters are analyzed on the operating well in order to obtain an improvement in the production performance.

\subsection{Gas Injection Depth}

The gas injection depth is the depth of the operating valve where the compressed gas enters the production tubing through the annulus. In well $\mathrm{C}-06$, the gas injection depth is analyzed from the lowest point of the production tubing at 8,700 feet up to 7,000 feet. The analysis is plotted in Figure 7 and the result is tabulated in Table 5. As obtained, the deeper the gas injection depth results in a higher liquid production rate. This phenomenon is due to more density of the fluid column in the tubing that can be reduced thus lighter fluid to be lifted (Hazarika, 2015).

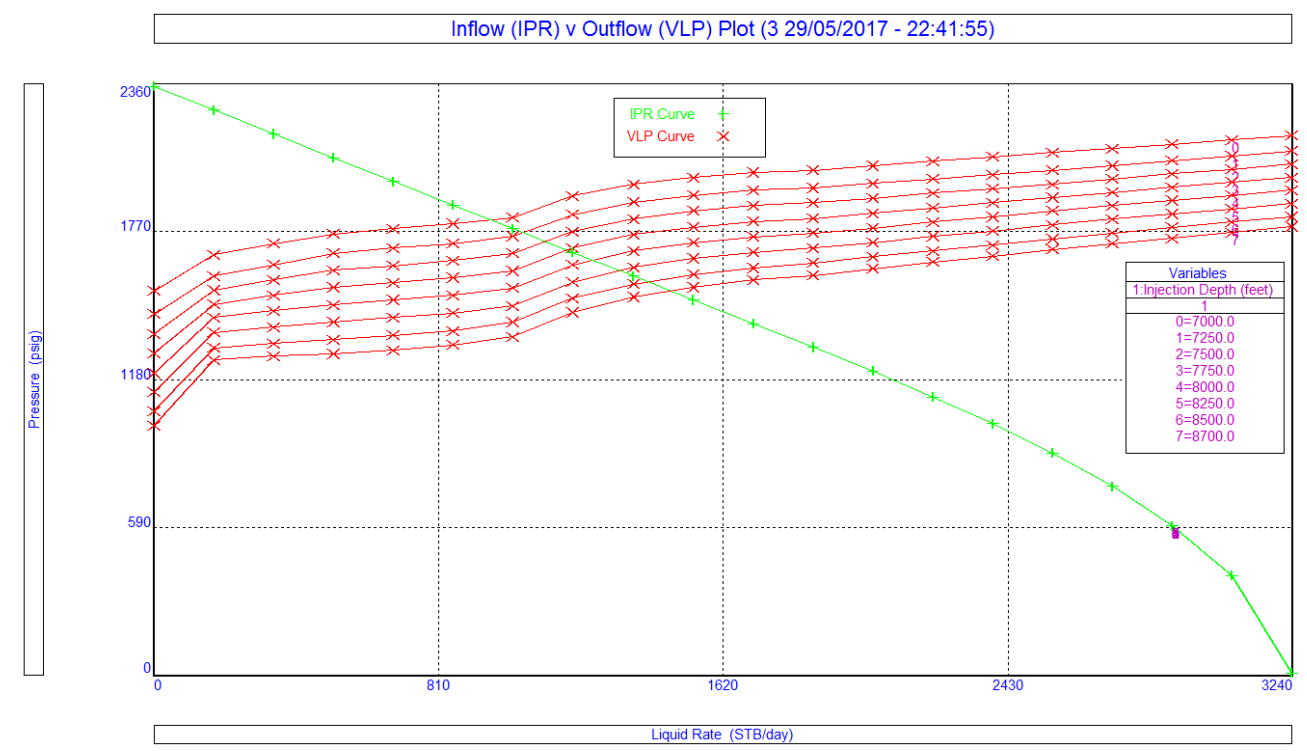

Figure7. Gas injection depth sensitivity analysis 
Evaluation of Continuous Gas Lift Systems in an Oil Well

Table5. Results of gas injection depth sensitivity analysis

\begin{tabular}{|c|c|}
\hline Injection Depth (ft.) & $\begin{array}{c}\text { Liquid Production Rate } \\
\text { (STB/day) }\end{array}$ \\
\hline 7000 & 962.0 \\
\hline 7250 & 1053.2 \\
\hline 7500 & 1116.9 \\
\hline 7750 & 1179.3 \\
\hline 8000 & 1251.9 \\
\hline 8250 & 1326.8 \\
\hline 8500 & 1405.8 \\
\hline 8700 & 1472.1 \\
\hline
\end{tabular}

\subsection{Gas Injection Rate}

The gas injection rate is the amount of compressed gas that is injected by the compressor from the surface down to the operating valve to reduce the density of the fluid column in the production tubing. Correspondingly, the increase of the gas injection rate increases the liquid production rate due to a lower density to be lifted up. An optimal injection rate that gives the highest production rate can be obtained by gradually increasing the gas injection rate wherein well C-06, the gas injection rate is manipulated from 5 to $20 \mathrm{MMscf} /$ day. Figure 8 plots the analysis of the gas injection rate where Table 6 tabulates the results of the injection rate manipulation.

It is observed that from 5 to $15 \mathrm{MMscf} / \mathrm{day}$, an increasing trend of liquid production rate is obtained from 928.7 to $1,655.1 \mathrm{STB} /$ day. However, on the gas injection rate of $20 \mathrm{MMscf} / \mathrm{day}$, the liquid production rate decreases to 1,564.4 STB/day. This behavior happens when the gas injection is still increased after the optimum rate is reached (Michael, 2015). Hence, a slippage between liquid and gas where the injected gas moves faster than the liquid phase hence dominating the upward movement of the fluid (Ebrahimi, 2010).

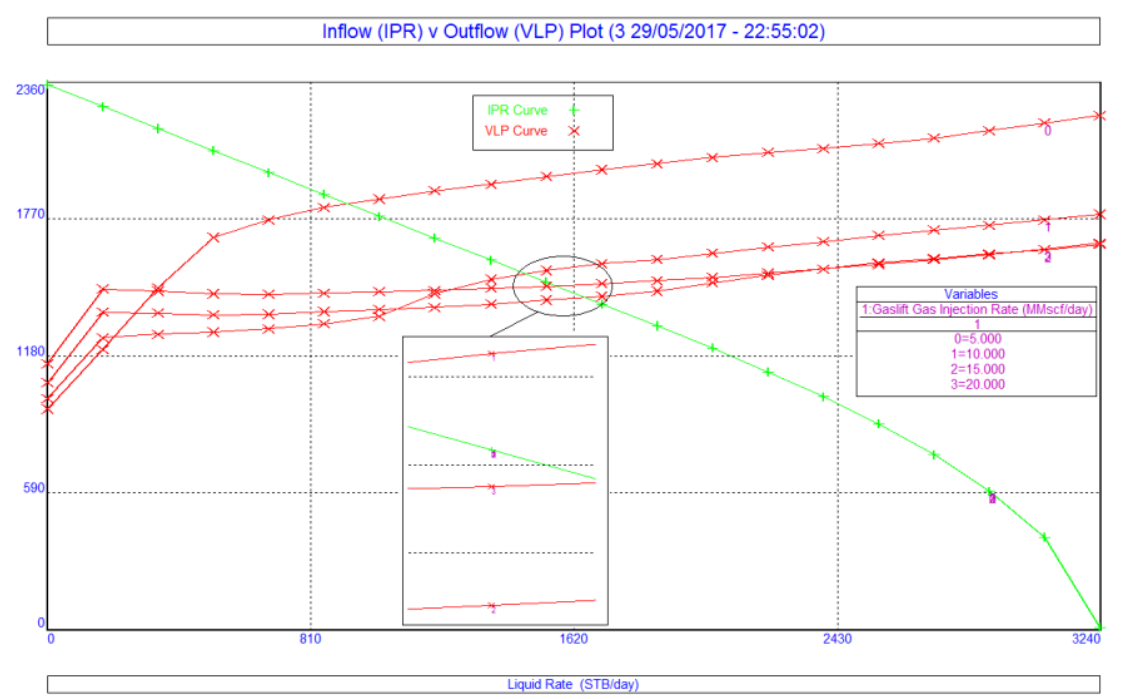

Figure8. Gas injection rate sensitivity analysis

Table6. Results of gas lift injection rate sensitivity analysis

\begin{tabular}{|c|c|}
\hline $\begin{array}{c}\text { Gas Lift Gas Injection Rate } \\
\text { (MMscf/day) }\end{array}$ & $\begin{array}{c}\text { Liquid Production Rate } \\
\text { (STB/day) }\end{array}$ \\
\hline 5 & 928.7 \\
\hline 10 & 1472.1 \\
\hline 15 & 1655.1 \\
\hline 20 & 1564.4 \\
\hline
\end{tabular}

\subsection{Gas Specific Gravity}

Gas specific gravity represents the density of the compressed gas used to be injected in the gas lift application. The range of the gas lift's gas specific gravity is between 0.55 to $1.0 \mathrm{sg}$ hence the analysis is done by manipulating the specific gravity within the given range. The behavior of continuous gas lift application towards a variation of gas specific gravity injected is shown in Figure 9 while the 
numerical results are listed down in Table 7. In accordance to the simulation, the denser the compressed gas injected results in a lower production rate. It occurs because the density of the compressed gas mixed with the high density of the fluid column into a new density to be produced once the compressed gas passes the operating valve. Hence, a denser compressed gas injected prevents an optimum density reduction in the fluid column.

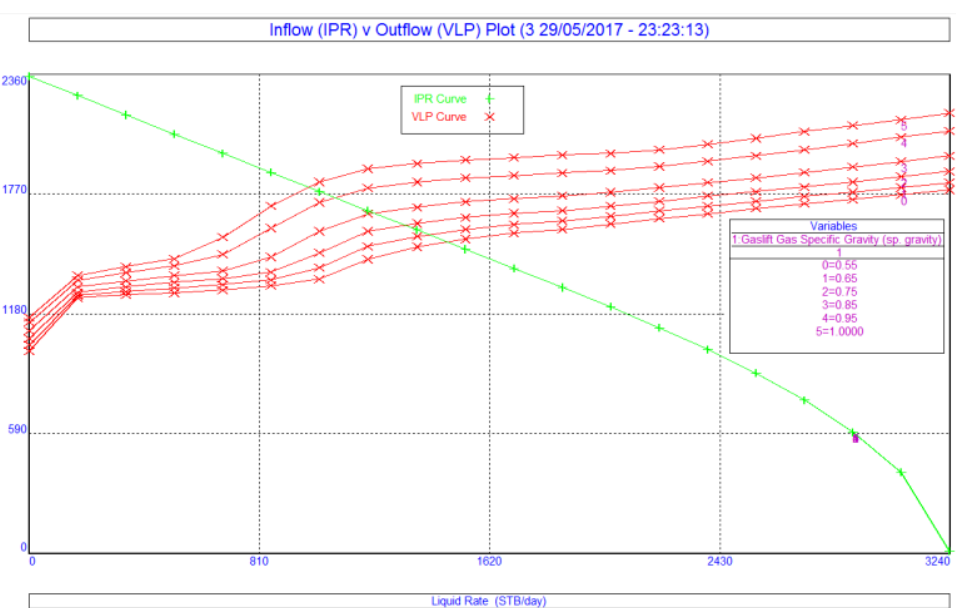

Figure9. Gas specific gravity sensitivity analysis

Table7. Results of gas specific gravity sensitivity analysis

\begin{tabular}{|c|c|}
\hline Gas Lift Gas Specific Gravity(sg) & Liquid Production Rate (STB/Day) \\
\hline 0.55 & 1472.1 \\
\hline 0.65 & 1407.3 \\
\hline 0.75 & 1324.7 \\
\hline 0.85 & 1213.4 \\
\hline 0.95 & 1079.8 \\
\hline 1 & 987 \\
\hline
\end{tabular}

\subsection{Wellhead Pressure}

Wellhead pressure or first node pressure is a pressure that exerted by the fluid at the top of the well. The main components of the wellheads are heads, spools and hanger of casing and tubing and suspension systems. The wellhead pressure needs to be combined with the hydrostatic pressure from the drill-string to obtain the flowing bottom-hole pressure which is used to determine the production rate of the well. In this analysis, the wellhead pressure is manipulated from 500 psig with a constant increment of 100 psig to 1,000 psig. Figure 10 plots the performance of continuous gas lift application towards the changes of wellhead pressure where the values are listed in Table 8. Accordingly, at the wellhead pressure of $500 \mathrm{psig}$, the well is producing 1,519.8 STB/day of oil while only 4,69STB/day at the wellhead pressure of $1,000 \mathrm{psig}$. Hence, the higher the wellhead pressure produces a lower liquid production rate. The increase of the well head pressure lowers the drawdown pressure in the bottom-hole hence more pressure is required to lift the fluid (Gamal, 2005).

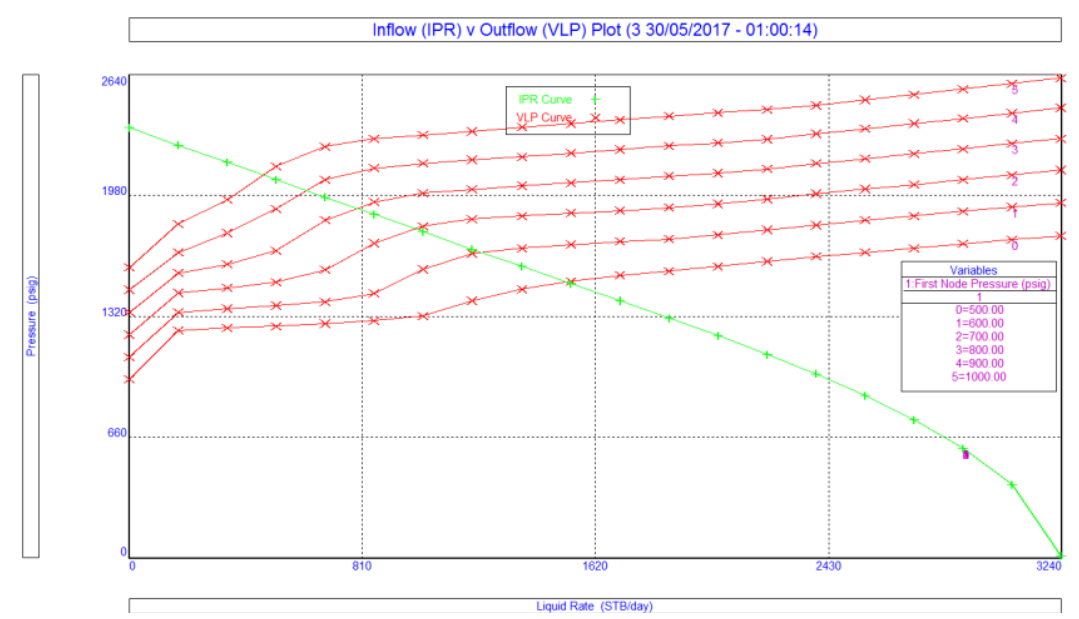

Figure10. Wellhead pressure sensitivity analysis 
Evaluation of Continuous Gas Lift Systems in an Oil Well

Table8. Results of wellhead pressure sensitivity analysis

\begin{tabular}{|c|c|}
\hline Wellhead Pressure (psig) & Liquid Production Rate (STB/Day) \\
\hline 500 & $1,519.8$ \\
\hline 600 & $1,229.1$ \\
\hline 700 & 998.8 \\
\hline 800 & 794.4 \\
\hline 900 & 620.4 \\
\hline 1,000 & 469.0 \\
\hline
\end{tabular}

\subsection{Sequential Optimization}

Sequential optimization is a method to obtain the optimized condition of a system by doing parameters analysis in sequence based where an optimum condition of each parameter analyzation is fixed before considering other parameters (Salazar-Mendoza, 2006). Hence, optimum manipulations from all the parameters are combined and the best outcome is achieved. The combination of the most suitable parameters is shown in Table 9 and plotted to Figure 11

Table9. Sequential optimization parameters

\begin{tabular}{|c|c|}
\hline Parameters & Values \\
\hline Gas injection depth (ft.) & 8700 \\
\hline Gas injection rate (MMscf/day) & 15 \\
\hline Gas specific gravity (sg) & 0.55 \\
\hline Wellhead pressure (psig) & 500 \\
\hline
\end{tabular}

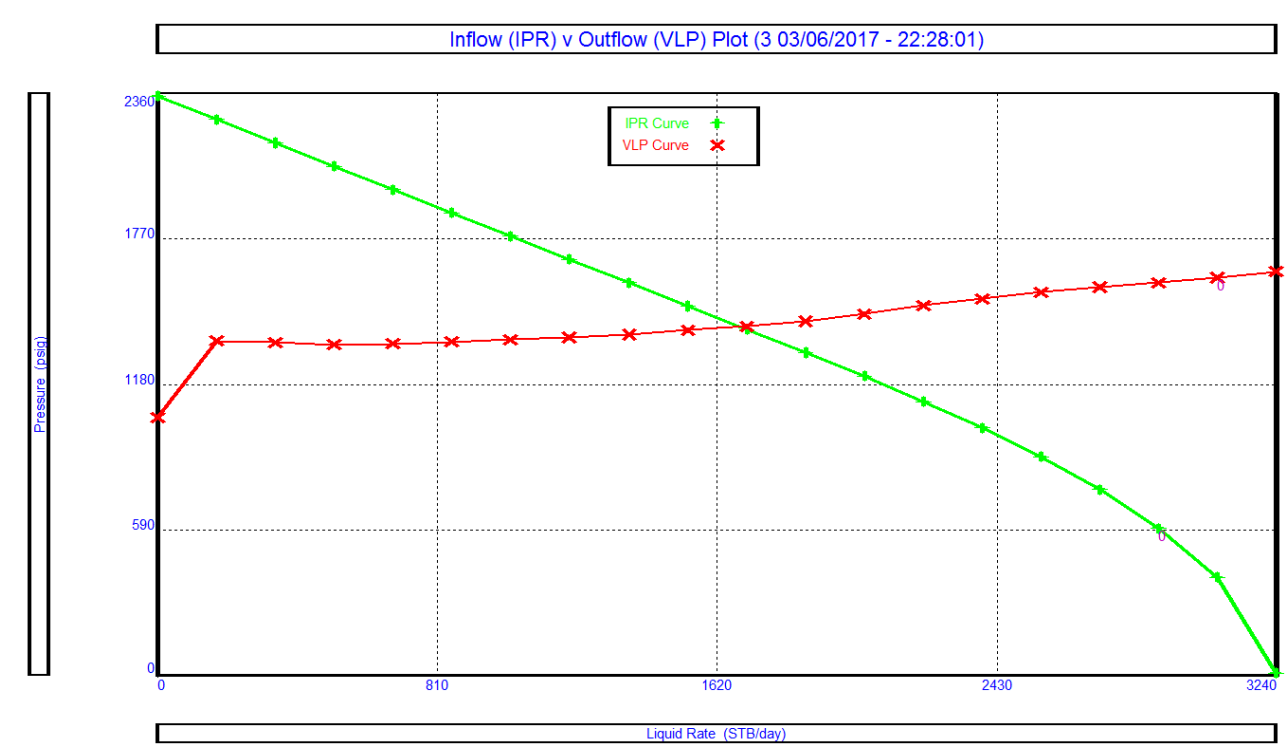

Figure11. Sequential optimization parameters IPR VS VLP plot

\section{Conclusion}

The conclusion of the evaluation of continuous gas lift application in an oil well are:

1. Selection of artificial lift method must be suitable to overcome both total well depth and total production rate of the desired well through initial well screening

2. The increase in water cut results in a lower production rate due to heavier liquid column density to be lifted up

3. The increase in reservoir pressure increases the production rate as more pressure to overcome the bottom-hole pressure

4. A deeper injection rate lets the compressed gas to reduce more of the fluid column's density hence higher production rate can be obtained

5. The production rate increases with the gas injection rate as long as the rate is still below the upper limit where the slippage between gas and liquid occurs

6. The least the specific gravity of the compressed gas injected gives a higher production rate 


\section{REFERENCES}

[1] Ahmed, T. \& Meehan, D. N. (2012). Advanced Reservoir Management and Engineering. Baker Hughes

[2] Hirsch, J. M., Stegemeier, G. L., Hall, J. W., Vinegar, H. J., Burnett, R. R., Savage, W. M. \& Carl, F. G. (2006). Use of Downhole High Pressure Gas in a Gas-lift Well and Associated Methods. United States Patent: US7147059B2

[3] Denney, D. (1999, November 1). A New Method for Determination of Reservoir Pressure. Society of Petroleum Engineers. doi:10.2118/1199-0062-JPT

[4] Boucher, A. R., Del Rio, C., Salazar, F., Milne, A. W., \& Robles, M. (2011, January 1). Increase Oil Production Without Increasing Water Cut in Ecuador Wells. Society of Petroleum Engineers. doi:10.2118/143777-MS

[5] Kaczorowski, N.J. (1993). Reservoir Limit Testing in Water-Drive Systems. Society of Petroleum Engineers. doi:10.2118/25336-MS

[6] Hazarika, S., Sinha, N., Bansal, R., \& Jayaram, R. (2015, November 24). Evaluation of Single Point Gas Lift System for a Deep Water Oil Field, India. Society of Petroleum Engineers. doi:10.2118/178087-MS

[7] Ebrahimi, M. (2010, June). Gas Lift Optimization in one of Iranian South Western Oil Fields. Society of Petroleum Engineers. doi:133434

[8] Michael, M. (2015, July 20). Automating Gas Lift Injection Rates Best Practices to Maximize Production. Unconventional Resources Technology Conference. doi:10.15530/URTEC-20152169308

[9] Gamal, A. A. (2005, Dec). Gas Lift and Gas Pumping. GUPCO In-house Publication.

[10] Salazar-Mendoza, R. (2006, January 1). A New Representative Curves for Gas-Lift Optimization. Society of Petroleum Engineers. doi:10.2118/104069-MS.

\section{AuthORS' BIOGRAPHY}

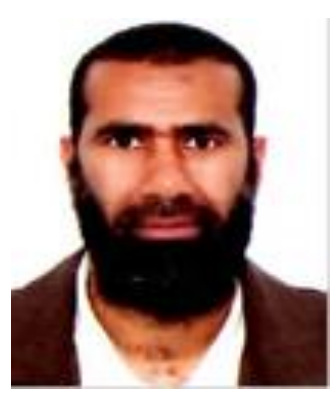

Hisham Khaled Ben Mahmud, has achieved Bachelor, Master and PhD degree in Chemical Engineering from Tripoli University, Sydney University and Curtin University, Australia, respectively. Also I have gained Graduate Diploma in oil and gas from University of Western Australia (UWA). I have expertise in modelling multiphase flow into subsea systems such as pipeline, jumper, riser evaluating pressure drop, and liquid holdup. Also optimize the risk of hydrate blockages into bend pipes. Recently I have involved into upstream research area including reservoir matrix acidizing, experimentally injecting a fluid (acid) into a core sample (sandstone or carbonate) to improve reservoir properties (porosity, permeability) observing wormhole and precipitation reaction. Another area I involve in is enhanced oil recovery (EOR) in brown oil field using different injecting fluids (CO2, water, polymer, surfactant) or modify production wells in order to improve hydrocarbon fluid recovery by minimizing oil wettability, surface tension and increase contact area.

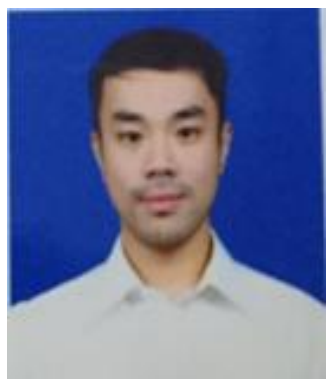

Vincent Goenawan, was born in Indonesia on March 18, 1994. He received the Bachelor of Engineering (Honors) in Petroleum Engineering from Curtin University, Malaysia. In 2015 - 2016, he was the president for Society of Petroleum Engineers (SPE) Curtin University Sarawak Student Chapter and had organized events such as Petroleum Exhibition, mud innovation, oil rig design competition and other technical events which collaborated with global oil and gas companies including Shell, Petronas, Halliburton and Ocean Care. He has received a Gold Standard Student Chapter Award under his term. He pursued his internship in Aspen Indo Aeroteknika, an insulation company in Indonesia and Based in US as an assistant of thermal insulation engineer. Throughout his internship period, he had lead projects in PT. Medco Energi InternatsionalTbk and PT. SulfindoAdiusaha with responsibilities of initiating technical query throughout the insulation process. 